DE

M E D I C I N A

T R O P I C A L

$\mathrm{DE}$

SÃO PAULO

JOURNAL OF THE SÃO PAULO INSTITUTE OF TROPICAL MEDICINE

Servicios de Salud de Hidalgo,

Coordinación de Investigación en Salud,

Pachuca, Hidalgo, México

Correspondence to: Imelda MenchacaArmenta

Servicios de Salud de Hidalgo,

Coordinación de Investigación en Salud Av. México, № 300 , Colonia Aquiles Serdán, C.P. 42039, Pachuca, Hidalgo, México

E-mail: imeldamenchacaa@gmail.com

Received: 18 July 2017

Accepted: 8 November 2017

\section{Risk perception and level of knowledge of diseases transmitted by Aedes aegypti}

Imelda Menchaca-Armenta, Moisés Ocampo-Torres, Arnulfo HernándezGómez, Karen Zamora-Cerritos

\section{ABSTRACT}

Diseases caused by viruses such as dengue, chikungunya and zika are mosquito-borne diseases transmitted by Aedes aegypti. We performed a cross-sectional study of healthcare personnel and the general population using questionnaires to identify the level of knowledge, attitudes and practices, and risk perception for dengue, chikungunya and zika. A total of 248 questionnaires were applied, $63.3 \%$ to healthcare personnel and $36.7 \%$ to the general population. Of the healthcare personnel, $53 \%$ were men, and in the general population $74 \%$ were women. Nahuatl and Spanish were spoken by both, healthcare personnel (28\%) and the general population (23\%). The level of knowledge, attitudes and practices and risk perception of the population and personnel showed significant differences $(p<0.05)$. Among healthcare personnel, nurses and vector operating staff had the lowest level of knowledge. On the other hand, the questions with the lowest scores were 1) symptoms of Zika in both groups, 2) circulating dengue serotypes in healthcare personnel and 3) symptoms of chikungunya in the general population. The results of this work allow us to identify information gaps in which knowledge, attitudes and practices, and risk perception need to be increased.

KEYWORDS: A. aegypti. Dengue. Chikungunya. Zika. Risk perception. KAP.

\section{INTRODUCTION}

Dengue, chikungunya and zika epidemics have been disseminating rapidly in the American continent causing a public health crisis. Dengue, chikungunya and zika viruses are transmitted by the mosquito species Aedes aegypti ${ }^{1,2}$. The incidence and epidemic of dengue virus infections have increased exponentially worldwide in the last 35 years. From 1970 to 1998, the number of cases of dengue quadrupled reaching 1.3 million with more than 3,600 deaths $^{3}$. In 2013, after confirmation of transmission of the chikungunya autochthonous virus in the Americas, the Pan American Health Organization (PAHO) together with the World Health Organization (WHO) emitted an epidemiological alert for chikungunya and dengue fever in the region ${ }^{4}$. In 2016, the WHO declared an international public health emergency regarding a cluster of microcephaly cases and Guillain-Barré syndrome in areas affected by Zika virus ${ }^{5}$.

Currently, the yellow fever vaccination is available ${ }^{6}$ and recently the first quadrivalent vaccination for the attenuated dengue virus has received commercial approval in Mexico, Brazil, The Philippines, El Salvador, Costa Rica, Paraguay, Guatemala, Peru, Indonesia, Thailand and Singapore ${ }^{7}$.

Therefore, preventive measures are based on the control of $A$. aegypti. Nevertheless, and despite efforts, it has not been possible to sustainably reduce the number of female egg-deposit sites, and even worse, a panorama of concern exists 
due to risk perception among families together with a wide margin of environmental and institutional vulnerability ${ }^{8}$.

Measures to increase the knowledge, attitudes and practice (KAP) regarding diseases transmitted by A. aegypti, particularly dengue, have been widely used to characterize communities and to evaluate interventions; however, there is controversy about the impact of KAP on prevention practices in the homes or behavioral changes ascribed by their inhabitants ${ }^{9,10}$. The knowledge acquisition is a factor in the generation of preventive behaviors, but its existence does not determine the appearance of healthy behaviors ${ }^{11}$. On the other hand, the perception of the risk of becoming ill seems to positively influence cleaning measures to eliminate mosquito breeding areas in patios ${ }^{12}$. In this work, our objective was to establish the level of KAP and risk perception of the population and healthcare personnel with regard to dengue, chikungunya, Zika and A. aegypti in the State of Hidalgo, Mexico.

\section{MATERIAL AND METHODS}

This was a cross-sectional descriptive study in the State

Table 1 - Survey for the recollection of data

\begin{tabular}{lc}
\hline Data & Participants \\
\hline Age & GP, HP \\
Sex & GP, HP \\
Male & \\
Female & GP, HP \\
Language & \\
Spanish & \\
Spanish and Nahualt & GP, HP \\
Other & \\
Education & \\
Primary & \\
Secondary & \\
Upper Secondary & \\
Bachelor's degree & \\
Specialist & \\
Graduate studies & \\
None & GP, HP \\
Occupation & \\
Housewife & \\
Employee & \\
Student & \\
Craftsperson/independent & \\
Other & \\
Position & \\
Director & \\
Program leader & \\
Physician & \\
Nurse & \\
Operative personnel & \\
Administrative personnel & \\
& \\
\hline
\end{tabular}

of Hidalgo in which two questionnaires were designed for healthcare personnel and the general population to determine their level of KAP and risk perception. Thirteen locations with the greatest incidence of dengue registered were selected from 2009 to 2014. Questionnaires were applied in March and April of 2016, in health centers and health jurisdictions. The sample size was of convenience. The questionnaires were applied to the population that came for consultation in the health clinics within two hours. At the same time, physicians and nurses caring for the population were surveyed.

Regarding the healthcare personnel, six categories of workers were surveyed: 1 ) directors, 2) vector, quality and epidemiology program workers, 3) physicians, 4) nurses, 5) vector operating staff and 6) administrative personnel. Before being surveyed, informed consent was obtained from all the participants.

The questionnaires were composed of the following sections: 1) socio-demographic characteristics, 2) knowledge of diseases transmitted by $A$. aegypti, symptoms and elimination of mosquito breeding areas and 3 ) perception of the diseases (Table 1). The questionnaires were scored using

\begin{tabular}{|c|c|}
\hline Have you ever been ill with dengue? & GP, HP \\
\hline \multicolumn{2}{|l|}{ Yes } \\
\hline \multicolumn{2}{|l|}{ No } \\
\hline \multicolumn{2}{|l|}{ Knowledge } \\
\hline $\begin{array}{l}\text { 1. Mention the name of the diseases } \\
\text { transmitted by } A \text {. aegypti }\end{array}$ & GP, HP \\
\hline \multicolumn{2}{|l|}{ a. Chagas } \\
\hline \multicolumn{2}{|l|}{ b. Chikungunya } \\
\hline \multicolumn{2}{|l|}{ c. Zika } \\
\hline \multicolumn{2}{|l|}{ d. Dengue } \\
\hline \multicolumn{2}{|l|}{ e. All } \\
\hline \multicolumn{2}{|l|}{ f. Unknown } \\
\hline 2. What is dengue? & GP, HP \\
\hline \multicolumn{2}{|l|}{ a. A virus } \\
\hline \multicolumn{2}{|l|}{ b. An illness } \\
\hline \multicolumn{2}{|l|}{ c. A Mosquito } \\
\hline \multicolumn{2}{|l|}{ d. Other } \\
\hline \multicolumn{2}{|l|}{ e. Unknown } \\
\hline 3. What is chikungunya? & GP, HP \\
\hline \multicolumn{2}{|l|}{ a. $A$ virus } \\
\hline \multicolumn{2}{|l|}{ b. An illness } \\
\hline \multicolumn{2}{|l|}{ c. A Mosquito } \\
\hline \multicolumn{2}{|l|}{ d. Other } \\
\hline \multicolumn{2}{|l|}{ e. Unknown } \\
\hline 4. What is Zika? & GP, HP \\
\hline \multicolumn{2}{|l|}{ a. $A$ virus } \\
\hline \multicolumn{2}{|l|}{ b. An illness } \\
\hline \multicolumn{2}{|l|}{ c. A Mosquito } \\
\hline \multicolumn{2}{|l|}{ d. Other } \\
\hline e. Unknown & \\
\hline
\end{tabular}


Table 1 - Survey for the recollection of data (cont.)

\section{How do you get dengue, chikungunya GP, HP and Zika?}

a. From person to person

b. Through coughing and/or sneezing

c. From the bite of any mosquito

d. When an $A$. aegypti mosquito infected with the virus bites a healthy person

e. Unknown

6. What are the symptoms of dengue? GP, HP

a. Conjuntivitis (red eyes)

b. Fever

c. Vomit

d. Bleeding

e. Muscle pain

f. Headache

g. Eye pain

h. Unknown

7. What are the symptoms of chikungunya?

a. Conjuntivitis (red eyes)

b. Fever

c. Muscle pain

d. Headache

e. Nausea

f. Fatigue

g. Rashes

h. Unknown

8. What are the symptoms of Zika?

a. Conjuntivitis (red eyes)

b. Fever

c. Muscle pain

d. Headache

e. Nausea

f. Fatigue

g. Rashes

h. Unknown

9. Mention the serotypes of dengue circulating in the region?

a. DENV-1 y DENV-2.

b. DENV-1 y DENV-3

c. DENV-3 y DENV-4

d. All

e. Unknown

10. Do you know what a breeding site is?

a. Yes

b. No

11. Mention places where mosquito larvae develop.

a. Containers with clean water, unchanged flower pots, old tires

b. Containers without waters

c. Closed water tanks with clean water

d. Open water tanks with dirty water

e. Other

12. How can we avoid mosquito larvae?

a. Vaccination

b. Fumigation

c. Using repellent

GP, HP

GP, HP

GP, HP

GP, HP d. Eliminating artificial containers that hold water

e. Using mosquito nets on doors and windows

f. Other

g. Unknown

13. How are breeding sites eliminated?

GP

a. Sweeping and throwing out trash

b. Dusting

c. Throwing out objects that aren't being used

d. Eliminating accumulated water

e. Cutting the grass

f. Unknown

Perception

1. What are the main health problems that GP, HP affect the community?

2. Who are at risk of getting sick from a GP, HP mosquito bite?

3. How serious can a mosquito bite be? GP, HP

a. Not serious

b. Serious

c. Deadly

d. Unknown

4. Do you consider that you could get sick GP, HP with dengue?

a. Yes

b. No

5. Do you consider that you could get sick GP, HP with chikungunya?

a. Yes

b. No

6. Do you consider that you could get sick GP, HP with zika?

a. Yes

b. No

7. Which of the three diseases transmited GP, HP by $A$. aegypti is the most serious?

HP a. Dengue

b. Chikungunya

c. Zika

d. All

e. Unknown

8. Why do you believe that people don't put into practice the recommendations to eliminate breeding sites?

a. They don't understand

b. Lack of interest

c. Laziness

d. Lack of information

e. Motive unknown

9. How would you rate the work of the vector program brigades to eliminate the

A. aegypti mosquito?

a. Good

b. Average

GP, HP

c. Insufficient

d. Bad

e. Unknown

HP: Healthcare personnel; GP: General population. 
a Likert scale as correct or incorrect. KAP levels and risk perception were obtained using the statistical mean of correct answers. Low scores were values below the mean, mid-level scores were values equal to the mean and high scores were values above the mean. The KAP level was constructed with ten items for healthcare personnel and with twelve items for the general population. The level of risk perception was obtained from nine items for both groups.

Data normality was evaluated using the KolmogorovSmirnov test. The chi square test was used to assess the significance of frequencies and $\mathrm{p}$ values $\leq 0.05$ were considered statistically significant. The statistical analysis was performed using IBM SPSS Statistics version 19 (IBM Corp. Armonk, NY, Corp). The study was approved by the Ethics and Research Committees of the Health Services of Hidalgo.

\section{RESULTS}

A total of 248 questionnaires were applied, of which $63.3 \%$ corresponded to the healthcare personnel and $36.7 \%$ to the general population. The mean age of the healthcare personnel was $38.1 \pm 12.1$ and of the general population was $39.1 \pm 15$. Regarding the gender, $53 \%$ of the healthcare personnel were men and $47 \%$ were women, in contrast with the general population in which $26 \%$ were men and $74 \%$ women. In relation to the language spoken, $28.03 \%$ stated that in addition to Spanish, they spoke Nahuatl, a percentage similar to that of the general population, in which $23 \%$ were bilingual. The educational level of the healthcare personnel was mainly a bachelor's degree (51\%), while in the general population most participants had studied only up to the secondary level (37\%). In regard to the question of having had dengue fever, $15 \%$ of the healthcare personnel stated that they had had the disease at some time, in comparison to the general population, in which the frequency was $7.4 \%$ (Table 2).

The level of knowledge of healthcare personnel regarding diseases transmitted by $A$. aegypti had a mean of $7.14 \pm 1.9$ correct answers; $50.3 \%$ had a high score, $29.9 \%$ a middle score, and $13.7 \%$ a low score. The general population had a mean of $6.64 \pm 1.87$ correct answers; $26.1 \%$, a high score; $36.4 \%$, a middle score and $37.5 \%$ had a low score. The level of knowledge was significantly higher in the healthcare personnel group. (Table 3).The questions that were more frequently correct among healthcare personnel were: 1) the transmission of dengue, chikungunya and Zika, 92.9\%, 2) dengue symptoms, $87.9 \%, 3$ ) name of the diseases transmitted by A. aegypti, $86.6 \%$, and 4 ) sites where mosquito larvae breed, $84.7 \%$. In contrast, the questions that were more frequently incorrect
Table 2 - Socio-demographic characteristics of study participants

\begin{tabular}{|c|c|c|}
\hline Data & $\begin{array}{l}\text { Healthcare } \\
\text { personnel }\end{array}$ & $\begin{array}{l}\text { General } \\
\text { population }\end{array}$ \\
\hline Age, years, mean & 38.17 & 39.1 \\
\hline Age range (SD) & $18-71(12.1)$ & $17-83(15.0)$ \\
\hline Sex & $N=157$ & $N=88$ \\
\hline Male & $83(53)$ & $24(26)$ \\
\hline Female & $74(47)$ & $67(74)$ \\
\hline \multicolumn{3}{|l|}{ Language } \\
\hline Spanish & $108(69)$ & $70(77)$ \\
\hline Spanish and Nahuatl & $44(28)$ & $21(23)$ \\
\hline Other & $5(3)$ & $0(0)$ \\
\hline \multicolumn{3}{|l|}{ Education } \\
\hline Primary & $3(2)$ & $21(23)$ \\
\hline Secondary & $16(10)$ & $34(37)$ \\
\hline Upper Secondary & $49(31)$ & $20(22)$ \\
\hline Bachelor's degree & $80(51)$ & $1(1)$ \\
\hline Specialist & $3(2)$ & $3(3)$ \\
\hline Graduate studies & $6(4)$ & $2(2)$ \\
\hline None & $0(0)$ & $10(11)$ \\
\hline \multicolumn{3}{|l|}{ Occupation } \\
\hline Housewife & - & $50(55)$ \\
\hline Employee & $157(100)$ & $18(20)$ \\
\hline Student & - & $3(3)$ \\
\hline Craftsperson/independent & - & $9(10)$ \\
\hline Other & - & $11(12)$ \\
\hline \multicolumn{3}{|c|}{ Have you ever been ill with dengue? } \\
\hline Yes & $24(15)$ & $7(8)$ \\
\hline No & $133(85)$ & $84(92)$ \\
\hline
\end{tabular}

were: 1) dengue serotypes circulating in the region $28 \%, 2$ ) symptoms of Zika virus infection, 50.3\%,3) symptoms of chikungunya fever, $65.6 \%$ and 4) definition of Zika virus infection, $68.1 \%$ (Figure 1).

Among the general population, the questions more frequently answered correctly were: 1) elimination of breeding sites, $90.2 \%, 2$ ) definition of breeding site, $84.9 \%, 3$ ) responsibility in eliminating breeding sites, $80.6 \%$ and 4 ) measures to avoid larvae reproduction, $79.6 \%$. The questions that were more frequently incorrectly answered were: 1) symptoms of Zika virus infection, $38 \%, 2)$ chikungunya fever symptoms, $42.9 \%, 3$ ) diseases transmitted by A. aegypti, 48.9\% and 4) transmission of dengue, chikungunya and Zika viruses, $54.8 \%$ (Figure 2). 
Table 3 - Level of knowledge of diseases transmitted by Aedes aegypti

\begin{tabular}{lccccc}
\hline Category & Low & Middle & High & $P$ & Total \\
\hline Population & $33(37.5)$ & $32(36.4)$ & $23(26.1)$ & .000 & 88 \\
Healthcare personnel & $31(19.7)$ & $47(29.9)$ & $79(50.3)$ & $102(41.6)$ & \\
\hline Total & $64(26.1)$ & $79(32.2)$ & 157 & 245 \\
\hline
\end{tabular}

Figures are shown as $\mathrm{n}(\%)$.

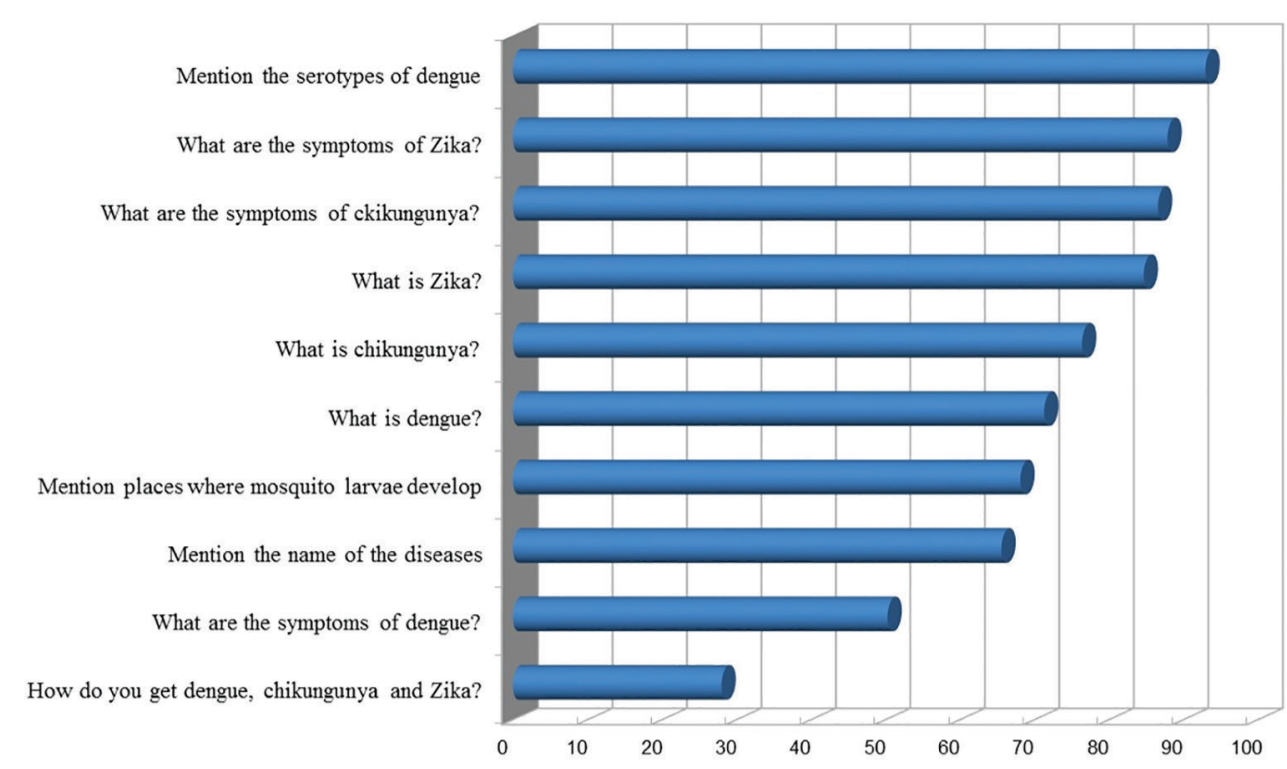

Figure 1 - Level of knowledge of healthcare personnel.

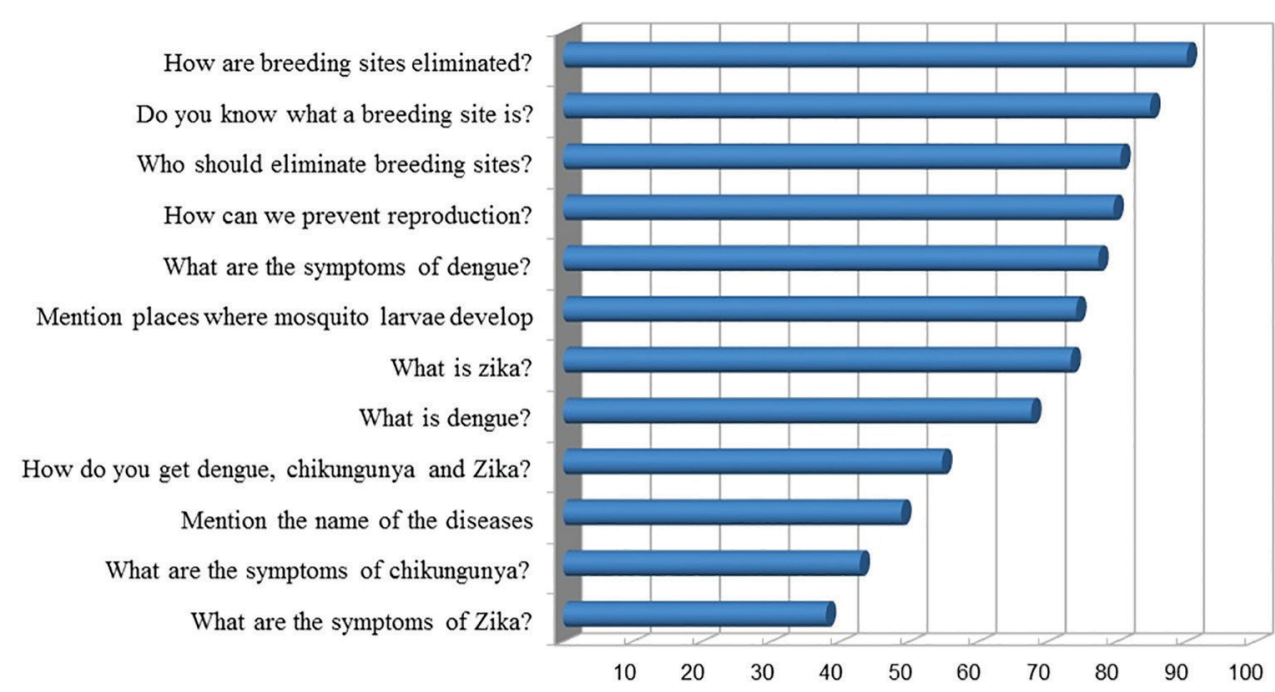

Figure 2 - Level of knowledge of the general population.

Likewise, the level of knowledge among the different categories of healthcare personnel presented frequencies equal to or less than $60 \%$ in high scores, except for the director category where $100 \%$ had a high level of knowledge. The category with the lowest frequency of high scores was the vector program operating staff with $48.8 \%$; this category had even lower scores than the administrative staff $(58.8 \%)$. In the categories of physicians and nurses working in primary care, the high score level of knowledge was between $50 \%$ and $42.2 \%$, respectively. The level of knowledge among categories of healthcare personnel was not significant (Table 4). 
Table 4 - Level of knowledge of healthcare personnel

\begin{tabular}{|c|c|c|c|c|c|c|c|c|c|}
\hline \multirow{2}{*}{ Healthcare personnel } & \multicolumn{4}{|c|}{ Level of knowledge } & \multicolumn{4}{|c|}{ Risk perception } & \multirow{2}{*}{ Tota } \\
\hline & Low & Middle & High & $P$ & Low & Middle & High & $P$ & \\
\hline Directors & $0(0)$ & $0(0)$ & $3(100)$ & 0.780 & $0(0)$ & $2(66.7)$ & $1(33.3)$ & 0.000 & 3 \\
\hline Program leaders & $2(13.3)$ & $4(26.7)$ & $9(60)$ & & $1(6.7)$ & $8(53.3)$ & $6(40)$ & & 15 \\
\hline Physician & $8(23.5)$ & $9(26.5)$ & $17(50)$ & & $3(8.8)$ & $25(73.5)$ & $6(17.6)$ & & 34 \\
\hline Nurses & $11(24.4)$ & 15 (33.3) & $19(42.2)$ & & $7(15.6)$ & $27(60)$ & $11(24.4)$ & & 45 \\
\hline Operative personnel & $7(16.3)$ & $15(34.9)$ & $21(48.8)$ & & $2(4.7)$ & $32(74.4)$ & $9(20.9)$ & & 43 \\
\hline Administrative personnel & $3(17.6)$ & $4(23.5)$ & $10(58.8)$ & & $1(5.9)$ & $16(94.1)$ & $0(0)$ & & 17 \\
\hline Total & $31(19.7)$ & $47(29.9)$ & $79(50.3)$ & & $14(8.9)$ & $110(70.1)$ & $33(21.0)$ & & 157 \\
\hline
\end{tabular}

Figures are shown as $\mathrm{n}(\%)$.

\section{Risk perception}

The level of perception of diseases transmitted by $A$. aegypti was $70 \%$ for healthcare personnel who had a middle score of risk perception, while $21 \%$ had a high score and $8.9 \%$ a low score (Table 5). The general population had a middle score of risk perception (63.3\%), 29.5\% had a low score and only $6.8 \%$ had a high score. It is notable that $30 \%$ of the general population had a low risk perception regarding diseases, such as dengue, chikungunya and Zika virus infections.

The healthcare personnel and the general population risk perception was based on the identification of the main health problems that affected their community; only $3 \%$ of the population considered any of the diseases transmitted by $A$. aegypti as a health problem, compared to $19 \%$ of the healthcare personnel. According to the perception of both groups, there are other diseases that represent a greater health problem such as acute respiratory infections that scored 36\%. Even when both groups considered that the entire population, encompassing all ages, is at risk of illness from the bite of A. aegypti, this perception is greater in healthcare personnel (56.7\%), and lower in the general population $(39.3 \%)$. Children were the second group considered more vulnerable to a mosquito bite by $13.4 \%$ of the general population and $28.6 \%$ of healthcare personnel. Regarding how serious a mosquito bite can be, $54 \%$ of those surveyed believed that the mosquito bite could be serious; this perception was more frequent in the general population (60\%) than among healthcare personnel (51\%). Of those surveyed, $35 \%$ felt that the mosquito bite was fatal. This perception was greater in healthcare personnel (39\%) than in the general population (26\%).

When asked if the person thought that they could contract dengue, $94.2 \%$ of healthcare personnel and $76.9 \%$ of the general population believed that this was possible. However, when asked about the possibility of getting sick with chikungunya and Zika viruses, $63.7 \%$ of the general population considered, with the same frequency for both diseases, that they could become sick, compared to healthcare personnel among whom $85.3 \%$ thought that they could become sick with chikungunya virus and $80.8 \%$ with Zika virus. In regard to the question of which of the three diseases transmitted by A. aegypti is more severe, both groups considered the three diseases severe. This perception was greater in the general population (47.2\%) in comparison to healthcare personnel (38.2\%).

A similar perception was found when participants were inquired about their opinion on why people do not carry out recommendations for eliminating egg breeding sites. Disinterest in this aspect was greater among the general population (40.6\%) than in the healthcare personnel $(45.2 \%)$. In addition, we inquired about the perception of the work of vector program brigades that remove $A$. aegypti mosquitos in their area. It was considered good by $57 \%$, regular by $20 \%$ and insufficient by $8 \%, 15 \%$ did not

Table 5 - Risk perception of diseases transmitted by Aedes aegypti

\begin{tabular}{|c|c|c|c|c|c|}
\hline \multirow[t]{2}{*}{ Category } & \multicolumn{3}{|c|}{ Risk perception } & \multirow[t]{2}{*}{$P$} & \multirow[t]{2}{*}{ Total } \\
\hline & Low & Moderate & High & & \\
\hline General population & $26(29.5)$ & $56(63.6)$ & $6(6.8)$ & .000 & $88(100)$ \\
\hline Healthcare personnel & $14(8.9)$ & $110(70.1)$ & $33(21.0)$ & & $157(100)$ \\
\hline Total & 40 (16.3) & $166(67.8)$ & $39(15.9)$ & & $245(100)$ \\
\hline
\end{tabular}

Figures are shown as $\mathrm{n}(\%)$. 
know what work they did. In contrast, $75 \%$ of healthcare personnel considered it good, $14 \%$ regular, $8 \%$ insufficient, $3 \%$ poor, and only $1 \%$ said they did not know. From a total of nine items, in eight statistically significant differences were found $(p=0.005)$, showing that risk perception was lower in the general population than in healthcare personnel. No significant differences were found with regard to how severe a mosquito bite could be $(\mathrm{p}=0.059)$.

Among the different categories of healthcare personnel, nurses had the lowest perception of risk (15.6\%). Although $60 \%$ of the nursing staff had an average risk level and $21.4 \%$ a higher risk level, the figure of $15.6 \%$ stands out in the low level because it is the highest figure at that level found in this study.

\section{DISCUSSION}

Several studies have confirmed the assumption that knowledge of dengue favors the adoption of preventive measures that promote the reduction of breeding sites for A. aegypti ${ }^{13}$. Another study has stated that the greater the knowledge, the greater the willingness to participate in research on dengue ${ }^{14}$. This study found that healthcare personnel have a greater knowledge and a greater risk perception in comparison with the general population. In this study, one third of the participants in the general population group had a maximum educational level of secondary school and their level of knowledge about the diseases transmitted by A. aegypti was low. In contrast, half of the healthcare personnel had a bachelor's degree and almost half of these workers had a high level of knowledge. Previous studies of KAP in dengue have associated the educational level of participants with better prevention attitudes ${ }^{15}$. Thus, the educational level in this work could have positively influenced a greater level of knowledge.

In contrast with studies in Thailand ${ }^{16}$, India ${ }^{17}$ and Nepal ${ }^{15}$, in which the majority of participants did not identify symptoms of dengue, in this work the general population showed optimum knowledge with respect to dengue symptoms, the identification of breeding sites and preventive measures. However, they had low knowledge regarding symptoms of chikungunya fever and Zika virus infection, as well as the transmission of both diseases. This lack of knowledge can be mainly attributed to the recent introduction of both viruses in the Americas ${ }^{18,19}$ and Hidalgo is not an exception, since in October 2015 the first case of chikungunya fever ${ }^{20}$ and one year later, in September 2016, the first case of Zika ${ }^{21}$ virus infection were confirmed.

Results on the identification of symptoms, transmission and preventive measures to fight dengue coincide with those reported in studies conducted in Jamaica ${ }^{22}$, Malaysia ${ }^{23}$, Australia $^{24}$ and India ${ }^{25}$; however, the limited level of knowledge of the general population regarding Zika virus infection and chikungunya fever influence the low level of knowledge of diseases transmitted by A. aegypti.

Although there are differences in the level of knowledge between healthcare personnel and the general population, both groups have a broad knowledge of dengue symptoms and preventive measures, in addition, the healthcare personnel has correctly identified the diseases transmitted by A. Aegypti. However, almost half of the healthcare personnel do not recognize the symptoms of Zika virus infections and a third do not recognize the serotypes of dengue that are circulating in the region. This question was exclusive for healthcare personnel and demonstrated the lack of knowledge beyond the campaigns implemented to reduce mosquito breeding sites. Studies performed in Taiwan ${ }^{26}$ and Ecuador ${ }^{27}$ have confirmed that knowledge of the epidemiology of dengue is limited among healthcare personnel, especially when asked about the endemicity of dengue in their region.

This study reflects the limited knowledge of healthcare personnel regarding Zika virus infection symptoms, findings that are not different from the world context. Similar results have been reported in Pakistan ${ }^{28}$ where healthcare personnel showed a low level of knowledge with regard to symptoms of this disease. One limitation of this work is that the questionnaires were carried out five months before confirming the first case of Zika in the State; therefore, the lack of knowledge or confusion of healthcare personnel is expected to have improved after national informative campaigns were implemented.

On the other hand, significant differences were found in risk perception in both groups. However, both groups did not perceive diseases transmitted by A. aegypti as a health problem in their community. From their point of view, diseases such as acute respiratory infections are more important major health problems, even though they consider that a mosquito bite can become severe and cause dengue, chikungunya or Zika virus infections. Both groups consider that the likelihood of dengue disease is greater than that of chikungunya and Zika virus infections. A study conducted in India showed that people with a low risk perception of mosquitos constitute a cause of morbidity and mortality because they do not identify mosquitoes as part of the problem related to the diseases transmited by them ${ }^{29}$. Knowledge of chikungunya fever transmission has been associated with a high probability of showing protective behaviors, even more than a high risk perception ${ }^{30}$.

Both study groups consider that people do not put into practice recommendations for eliminating breeding sites 
because of a lack of interest. Finally, we inquired about the perception of the work of vector program brigades that remove A. aegypti mosquitos in their area and $57 \%$ of the general population considered their work good. The results obtained confirmed the strategy of prevention and control that have been implemented nationally and which Hidalgo has joined.

Another limitation of our study is that the work was conducted in areas defined as endemic to dengue, which could influence in a greater level of knowledge in comparison to non-endemic areas, which have a lower exposition to prevention campaigns and mosquito control. Another limitation of the study is that the population interview was performed in health centers, where the population remained waiting to be attended. Nevertheless, the level of knowledge and the risk perception could vary within the population, for example, in students, senior citizens, socioeconomic levels or a gender-focused analysis. Several studies have shown differences in the knowledge among populations, such as students ${ }^{31}$, health professionals ${ }^{27}$ and even the level of exposition to the media with messages related to dengue ${ }^{32}$. On the other hand, the gender-focus analysis could be considered as a socially explanatory element of the roles that men and women play in different environments (domestic, community and social) and that modulates the risk of exposition to the vector ${ }^{33}$.

\section{CONCLUSIONS}

The level of knowledge and risk perception significantly differed between groups. The level of knowledge observed was higher among healthcare personnel, but there were differences between its categories. Nursing and operating vector program staff showed less knowledge even though the latter group by the nature of their work was more exposed to mosquito bites, a fact that was confirmed by the results of previous dengue surveys. Studies similar to this one allow identifying information gaps for the design of strategies to increase KAP in specific groups. Although the occurrence of diseases such as Zika virus infections and chikungunya fever in our country and State is relatively recent, measures to control the vector continue to focus on the identification and elimination of mosquito breeding sites, without increasing the knowledge beyond questions such as the distribution of serotypes in the region, which come from the main message of campaigns and should be specific to the personnel, particularly the operating vector program staff to increase their understanding on the vector population dynamics and the epidemiology of diseases transmitted by A. aegypti.

\section{FUNDING}

This study was funded by Servicios de Salud de Hidalgo.

\section{REFERENCES}

1. Diagne CT, Faye O, Guerbois M, Knight R, Diallo D, Faye O, et al. Vector competence of Aedes aegypti and Aedes vittatus (Diptera: Culicidae) from Senegal and Cape Verde archipelago for West African lineages of chikungunya virus. Am J Trop Med Hyg. 2014;91:635-41.

2. Ioos S, Mallet HP, Leparc Goffart I, Gauthier V, Cardoso T, Herida M. Current Zika virus epidemiology and recent epidemics. Med Mal Infect. 2014;44:302-7.

3. Guzmán MG, García G, Kourí G. El dengue y el dengue hemorrágico : prioridades de investigación. Ver Panam Salud Publica. 2006;19:204-15.

4. Organización Panamericana de la Salud. Fiebre por chikungunya y dengue en las Américas: alerta epidemiológica. [cited 2017 Feb 2]. Available from: http://www.paho.org/par/ index.php?option=com_content $\&$ view $=$ article $\&$ id $=1190$ : fiebre-por-chikungunya-y-dengue-en-las-americas-alertaepidemiologica- $\&$ Itemid $=258$

5. Pan American Health Organization. WHO announces a Public Health Emergency of International Concern. [cited 2017 Nov 9]. Available from: http://www.paho.org/hq/index. php?option=com_content $\&$ view=article $\&$ id $=11640 \&$ Itemid $=135 \&$ lang $=\mathrm{e}$

6. Barwick Eidex R. History of thymoma and yellow fever vaccination. Lancet. 2004;364:936.

7. Sanofi Pasteur. Primera vacuna contra el dengue aprobada en más de 10 países. [cited 2017 Oct 09]. Available from: http:// www.sanofipasteur.com/es/articles/primera_vacuna_contra_ el_dengue_aprobada_en_mas_de_10_paises.aspx

8. Cifuentes E. Factores ambientales que determinan la aparición de brotes y la persistencia del dengue en Morelos. Salud Publica Mex. 2007;49:E114-6.

9. Castro Peraza M, Gálvez Miranda C, Sanchez Váldes L, Pérez Chacón D, Polo Díaz V, Concepción Díaz D, et al. Encuesta poblacional sobre conocimiento y percepciones acerca de dengue contra prácticas preventivas en el municipio Lisa. Rev Cubana Med Trop. 2010;62:245-53.

10. Rosenbaum J, Nathan MB, Ragoonanansingh R, Rawlins S, Gayle $\mathrm{C}$, Chadee DD, et al. Community participation in dengue prevention and control: a survey of knowledge, attitudes, and practice in Trinidad and Tobago. Am J Trop Med Hyg. 1995; 53: 111-7.

11. Parks W, Lloyd L. Planning social mobilization and communication for dengue fever prevention and control: a step-by-step guide. Geneva: WHO; 2004. 
12. Castro M, Sánchez L, Pérez D, Sebrango C, Shkedy Z, Van der Stuyft P. The relationship between economic status, knowledge on dengue, risk perceptions and practices. PLoS One. 2013;8:e81875.

13. Mejía R, Ribó A, Quinteros E, López A, Villegas P, Vela XF, et al. Knowledge attitude and practices related on prevention of mosquito borne diseases and sanitation conditions in a Salvadoran urban community. Occup Dis Environ Med. 2016;4:83-102.

14. Harapan H, Anwar S, Bustaman A, Radiansyah A, Angraini $\mathrm{P}$, Fasli R, et al. Community willingness to participate in a dengue study in Aceh Province, Indonesia. PLoS One. 2016;11:e0159139.

15. Dhimal M, Aryal KK, Dhimal ML, Gautam I, Singh SP, Bhusal $\mathrm{CL}$, et al. Knowledge, attitude and practice regarding dengue fever among the healthy population of highland and lowland communities in Central Nepal. PLoS One. 2014;9:e102028.

16. Van Benthem BH, Khantikul N, Panart K, Kessels PJ, Somboon P, Oskam L. Knowledge and use of prevention measures related to dengue in northern Thailand. Trop Med Int Health. 2002;7:993-1000.

17. Ashok Kumar V, Rajendran R, Manavalan R, Tewari SC, Arunachalam N, Ayanar K, et al. Studies on community knowledge and behavior following a dengue epidemic in Chennai city, Tamil Nadu, India. Trop Biomed. 2010;27:330-6.

18. Weaver SC, Osorio JE, Livengood JA, Chen R, Stinchcomb DT. Chikungunya virus and prospects for a vaccine. Expert Rev Vaccines 2012;11:1087-101.

19. Rodríguez-Morales AJ. Zika: the new arbovirus threat for Latin America. J Infect Dev Ctries. 2015;9:684-5.

20. México. Sistema Nacional de Vigilancia Epidemiológica. Casos por entidad federativa de enfermedades de interés local, regional o institucional hasta la semana epidemiológica 39. E. V. Chikungunya hasta la 40 del 2015. Cuadro 11. Bol Epidemiol. 2015;40:38. [cited 2017 Nov 11] Available from: https://www.gob.mx/cms/uploads/attachment/file/25078/ sem40.pdf

21. México. Sistema Nacional de Vigilancia Epidemiológica. Casos por entidad federativa de enfermedades transmitidas por vector hasta la semana epidemiológica 33 del 2016. Cuadro 7.2. Bol Epidemiol. 2016;33:35. [cited 2017 Nov 11]. Available from: https://www.gob.mx/cms/uploads/attachment/file/129562/ sem33.pdf
22. Shuaib F, Todd D, Campbell-Stennett D, Ehiri J, Jolly PE. Knowledge, attitudes and practices regarding dengue infection in Westmoreland, Jamaica. West Indian Med J. 2010;59:139-46.

23. Wong LP, Shakir SM, Atefi N, AbuBakar S. Factors affecting dengue prevention practices: Nationwide survey of the Malaysian public. PLoS One. 2015;10:e0122890.

24. Gyawali N, Bradbury RS, Taylor-Robinson AW. Knowledge, attitude and recommendations for practice regarding dengue among the resident population of Queensland, Australia. Asian Pac J Trop Biomed. 2016;6:360-6.

25. Valantine B, Kumar RP, Vasudevan S, Sureshbabu J, Singh Z. Cross sectional study on knowledge, attitude and practice regarding dengue among adult population visiting a tertiary care hospital in Puducherry, India. Int J Community Med Public Heal. 2017;4:623-7.

26. Ho TS, Huang MC, Wang SM, Hsu HC, Liu CC. Knowledge, attitude, and practice of dengue disease among healthcare professionals in southern Taiwan. J Formos Med Assoc. 2013;112:18-23.

27. Handel AS, Ayala EB, Borbor-Cordova MJ, Fessler AG, Finkelstein JL, Espinoza RX, et al. Knowledge, attitudes, and practices regarding dengue infection among public sector healthcare providers in Machala, Ecuador. Trop Dis Travel Med Vaccines. 2016;2:8.

28. Iffat W, Shakeel S, Fasih F. Pakistani healthcare practitioners' understanding of the Zika Virus disease. J Health Educ Res Dev. 2016;4:1000185.

29. Patel AB, Rathod H, Shah P, Patel V, Garsondiya, J, Sharma R. Perceptions regarding mosquito borne diseases in an urban area of Rajkot City. Natl J Med Res. 2011;1:45-7.

30. Moro ML, Gagliotti C, Silvi G, Angelini R, Sambri V, Rezza G, et al. Knowledge, attitudes and practices survey after an outbreak of chikungunya infections. Int Health. 2010;2:223-7.

31. Ibrahim NK, Al-Bar A, Kordey M, Al-Fakeeh A. Knowledge, attitudes, and practices relating to Dengue fever among females in Jeddah high schools. J Infect Public Health. 2009;2:30-40.

32. Boonchutima S, Kachentawa K, Limpawithayakul M, Prachansri A. Longitudinal study of Thai people media exposure, knowledge, and behavior on dengue fever prevention and control. J Infect Public Health 2017;10:836-41.

33. Arenas-Monreal L, Piña-Pozas M, Gómez-Dantés H. Aportes y desafíos del enfoque de género en el estudio de las enfermedades transmitidas por vector. Salud Publica Mex 2015;57:66-75. 